\title{
ADAPTING THE TREATMENT OF OVARIAN CYSTS ACCORDING TO THEIR TYPE IN DAIRY CATTLE
}

\author{
Silviu-Ionuț BORȘ ${ }^{1, *}$, Alina BORȘ ${ }^{2}$ \\ *E-mail: bors.ionut@yahoo.com
}

Received: Feb. 15, 2021. Revised: Mar. 05, 2021. Accepted: Mar. 16, 2021. Published online: May 21, 2021

\begin{abstract}
Ovarian cysts, estimated as the most frequent ovarian disorder in dairy cattle, can impact the economic aspect and trigger serious loss by affecting the reproductive performance. However, treatment strategies for ovarian cysts in dairy cattle are disputed, as some researchers favour the use of gonadotropin-releasing hormone $(\mathrm{GnRH})$ for all cysts, whereas others recommend this treatment only for follicular cysts, with prostaglandin F2 $\alpha$ (PGF2 $\alpha$ ) for luteal cysts, but not all of the dairy cattle responded to these regimes. Other studies mention a spontaneous recovery for some of the dairy cattle that present this disorder. However, the Ovsynch protocol appears to be the most used for treating ovarian follicular cysts, despite low pregnancy rates. Thus, this study's main purpose is to assess by analogy the reproductive efficiency of multiparous dairy cattle with follicular cysts after treatment with a recommended dose of GnRH or a further Ovsynch protocol, and of cattle with luteal cysts after PGF $2 \alpha$ or a further 12-day Presynch protocol, by
\end{abstract}

comparing the reproductive responses between treated and non-treated cattle. It is remarkable that ten of the dairy cattle diagnosed with ovarian cysts recovered spontaneously without any hormonal intervention, but the reproductive performance indicates that treatment should be started as soon as the condition is diagnosed. Compared with other studies, our approach improved the conception $(82.4 \%$ and $64.3 \%$, respectively) and pregnancy rates $(53.8 \%$ and $50 \%$, respectively) in both follicular and luteal cysts.

Keywords: anovulation; treatment; estrus; reproduction.

\section{INTRODUCTION}

Dairy cattle failing to achieve a one-yearcalving-to-conceptioninterval is clear indication of a reproductive inefficiency, which can cause significant economic loss. Reproductive inefficiency is mainly

\footnotetext{
${ }^{1}$ Research and Development Station for Cattle Breeding, Dancu, laşi, Romania

2 Faculty of Veterinary Medicine, lasi University of Life Sciences, Romania
} 


\section{S. I. BORȘ, Alina BORȘ}

provoked by delayed cyclicity or anovulation and prolonged luteal phase (Opsomer et al., 1998). Ovarian cysts are decisive in causing reproductive inefficiency in dairy cattle.

Dairy cattle ovarian cysts, both follicular and luteal, are described as anovulatory ovarian structures that present a cavity larger than $20 \mathrm{~mm}$ in diameter where a corpus luteum is absent. These structures combine signs and symptoms specific to a hormonal disorder and ovarian dysfunction, a condition connected with several environmental and genetic factors that induce a heterogeneous clinical and biochemical phenotype (Borş et al., 2020).

Abdalla et al.'s recent study (2020) revealed better pregnancy rates per artificial insemination (AI) for dairy cattle with ovarian follicular cysts that had received pretreatment with gonadotropin-releasing hormone (GnRH) up to the moment where the luteal structure was spotted, prior to starting the Ovsynch treatment regimen.

Thus, this present study aims to evaluate the application of two different hormonal protocols according to cyst type - GnRH or a further Ovsynch protocol for follicular cysts and prostaglandin F2 $\alpha$ (PGF2 $\alpha$ ) or a further 12-day Presynch protocol for luteal cysts - by comparing oestrus, conception and pregnancy rates and diagnosis-to-oestrus and calving-to-conception intervals in treated versus non-treated multiparous dairy cattle.

\section{MATERIALS AND METHODS}

\section{Animals and study design}

This study was conducted on 77 multiparous Holstein Friesian dairy cattle housed in a dairy farm located in northeastern Romania. During the study period, the farm milked approximately 330 medium-producing dairy cattle twice a day, with a daily average of $26 \mathrm{~kg}$ of milk per cow per day. The dairy cattle were housed in free stall barns with concrete floors covered with mattresses and were fed a total mixed ration (TMR) twice a day, with water ad libitum. Standard management practices were followed to maintain healthy animals. Each cow had a voluntary waiting period of 45 days in milk. Oestrus detection was carried out twice a day (early in the morning and late in the evening) by an experienced veterinarian using visual examination of the animal for at least 30 min. The oestrus signs were: attempting to mount other dairy cattle; chasing herd mates; restlessness; chinresting; sniffing the vagina of herd mates; bellowing; congestion; relaxation, and mucus discharge from the vulva. The manifestation of standing oestrus was considered to be a sign of true oestrus. The dairy cattle suspected to be in oestrus were clinically examined and only those with physiologically normal, clear and viscous mucus were inseminated in order to maximize the chances of pregnancy.

An AI technician used semen from a single bull to serve the selected dairy cattle approximately $12 \mathrm{~h}$ after the onset of oestrus (one straw per cow, one insemination per oestrus). One experienced veterinarian conducted all the ultrasound examinations and hormone injections. Transrectal ultrasonography (WED $3000 \mathrm{~V}$, Shenzhen Well.D Medical Electronics Co., Ltd., China) was performed 25 days after AI and repeated on Day 45 for 


\section{HORMONAL TREATMENTS OF OVARIAN CYSTS IN DAIRY CATTLE}

pregnancy confirmation. Ultrasound scanning of the uterus and ovaries was processed using a $5.5-7 \mathrm{MHz}$ rectal linear probe for treatment and confirmation of pregnancy. All the dairy cattle that were not artificially inseminated until 60 days' or more postpartum were examined (the infertility exam) in order to identify the ovarian cysts. Based on the literature, dairy cattle presenting ovarian cysts were identified as displaying ovarian cavity structures with a diameter greater than $20 \mathrm{~mm}$ (Bartolome et al., 2005), along with a flaccid uterus where a luteal structure is absent (Jeengar et al., 2014; Vanholder et al., 2006).

Cysts with walls thicker than $3 \mathrm{~mm}$ and a grey echogenic aspect were considered to be luteal cysts, whereas cysts defined by wall thickness less than or equal to $3 \mathrm{~mm}$ and a uniformly anechogenic antrum were categorized as follicular (Brito and Palmer, 2004). Furthermore, dairy cattle with a history of clinical diseases such as endometritis, mastitis, lameness and digestive disorders, or diagnosed with clinical endometritis by transrectal palpation, were not used in this study. Taking into consideration the small number of primiparous, compared with multiparous cows diagnosed with ovarian cysts, for this study we included only multiparous cows. This experimental design resulted in four subject groups: multiparous dairy cattle diagnosed with follicular cysts and treated (experimental EFC group, $n=26$; parity $2=19$, parity $3=7$ ); diagnosed with follicular cysts and not treated (control MFC group, $n=18$; parity $2=13$, parity $3=5$ ); diagnosed with luteal cysts and treated (experimental ELC group, $n=18$; parity $2=14$, parity $3=4$ ), and diagnosed with luteal cysts and not treated (control MLC group, $n=15$; parity $2=13$, parity $3=2$ ).
The multiparous dairy cattle from the experimental groups diagnosed with different ovarian cysts and no apparent uterine disease received an intramuscular dose of either GnRH (21 $\mu \mathrm{g}$ buserelin acetate, $5 \mathrm{ml}$ Receptal; MSD Animal Health, Boxmeer, The Netherlands) for treating follicular cysts or $500 \mu \mathrm{g}$ cloprostenol (2 $\mathrm{ml}$ Estrumate; MSD Animal Health, The Netherlands) for treating luteal cysts. For dairy cattle from the EFC group with no response after this first hormonal dose of GnRH $(21 \mu \mathrm{g}$ buserelin acetate, $5 \mathrm{ml}$ Receptal; MSD Animal Health, Boxmeer, The Netherlands) on Day 0, the Ovsynch protocol (Fig. 1) was used by continuing the treatment with PGF2 $\alpha \quad(500 \mu \mathrm{g}$ cloprostenol, $2 \mathrm{ml}$ Estrumate; MSD Animal Health, Boxmeer, The Netherlands) on Day 7, a second dose of GnRH $(10 \mu \mathrm{g}$ buserelin acetate, $2.5 \mathrm{ml}$ Receptal; MSD Animal Health, Boxmeer, The Netherlands) 2 days after the PGF2 $\alpha$ and AI 12-24 h later. For dairy cattle from the ELC group not responding to a single dose of PGF $2 \alpha$ on Day 0, the 12-day Presynch protocol (Fig. 2) was used.

\section{Statistical analysis}

The chi-square test was used to compare the oestrus rates, conception rates per total number of inseminated dairy cattle and pregnancy rates per total number of treated dairy cattle between the experimental and control groups (EFC group vs. MFC group; ELC group vs. MLC group). Differences between the same groups with respect to the diagnosisto-oestrus interval and calving-toconception interval were evaluated using the Mann-Whitney U-test. Statistically significant differences between variables were determined at $P<0.05$. 


\section{S. I. BORȘ, Alina BORȘ}

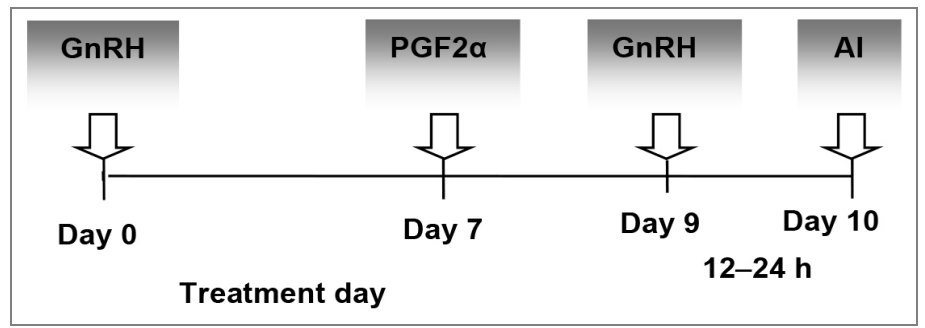

Figure 1 - The Ovsynch protocol used for treating ovarian follicular cysts in dairy cattle

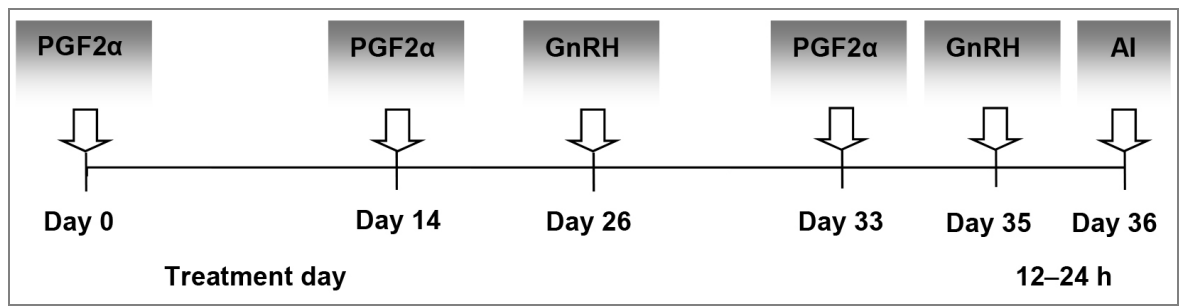

Figure 2 - The 12-day Presynch protocol used for treating ovarian luteal cysts in dairy cattle

\section{RESULTS AND DISCUSSION}

The present study investigated the reproductive response of multiparous dairy cattle diagnosed with follicular cysts to a recommended dose of GnRH or a further Ovsynch protocol and of cattle with luteal cysts to PGF2 $\alpha$ or a further 12-day Presynch protocol. Thus, the Ovsynch and 12-day Presynch protocols were used complementarily only for those cattle not responding to the single dose of GnRH or PGF2 $\alpha$ to increase the pregnancy rate. There was a significant difference between oestrus rates in dairy cattle from experimental groups, compared with control groups diagnosed with follicular and luteal cysts that were treated with, respectively, GnRH or a further Ovsynch protocol $(65.4 \%$ vs. $27.8 \%$, $P<0.05)$ and PGF $2 \alpha$ or a further 12-day Presynch protocol (77.8 vs. $33.3 \%, P<0.05)$. Similarly, differences were recorded for conception rates (82.4\% vs. $40 \%, P<0.05 ; 64.3 \%$ vs. $40 \%, P<0.05)$ and pregnancy rates (53.8 vs. $11.1 \%, P<0.05 ; 50$ vs. $13.3 \%, \quad P<0.05)$ between treated versus non-treated groups diagnosed with follicular or luteal cysts. It is interesting that $27.8 \%$ of dairy cattle diagnosed with follicular cysts and $33.3 \%$ of dairy cattle diagnosed with luteal cysts showed oestrus without any treatment, these being considered as presenting a spontaneous recovery (Table 1).

However, the diagnosis-tooestrus and calving-to-conception intervals showed the lowest values $(P<0.05)$ for the treated dairy cattle compared with the non-treated cattle for both follicular and luteal cysts (Table 1). 
Table 1 - Reproductive parameters of follicular and luteal cysts groups (EFC group vs. MFC group, ELC group vs. MLC group)

\begin{tabular}{|c|c|c|c|c|}
\hline \multirow[b]{2}{*}{ Reproductive parameters } & \multicolumn{2}{|c|}{$\begin{array}{l}\text { Follicular cysts } \\
\qquad(n=44)\end{array}$} & \multicolumn{2}{|c|}{$\begin{array}{l}\text { Luteal cysts } \\
\qquad(n=33)\end{array}$} \\
\hline & $\begin{array}{c}\text { EFC } \\
\text { group } \\
(n=26)\end{array}$ & $\begin{array}{c}\text { MFC } \\
\text { group } \\
(n=18)\end{array}$ & $\begin{array}{c}\text { ELC } \\
\text { group } \\
(n=18)\end{array}$ & $\begin{array}{c}\text { MLC } \\
\text { group } \\
(n=15)\end{array}$ \\
\hline Oestrus rate (\%) & $\begin{array}{c}65.4^{\mathrm{a}} \\
(17 / 26)\end{array}$ & $\begin{array}{l}27.8^{\mathrm{b}} \\
(5 / 18)\end{array}$ & $\begin{array}{c}77.8^{\mathrm{a}} \\
(14 / 18)\end{array}$ & $\begin{array}{l}33.3^{\mathrm{b}} \\
(5 / 15)\end{array}$ \\
\hline $\begin{array}{l}\text { Diagnosis-to-oestrus interval, } \\
\text { days (mean } \pm \text { SD) }\end{array}$ & $8.5 \pm 2^{c}$ & $59.2 \pm 19^{d}$ & $19 \pm 6^{c}$ & $60.2 \pm 12^{d}$ \\
\hline $\begin{array}{l}\text { Calving-to-conception interval, } \\
\text { days (mean } \pm \text { SD) }\end{array}$ & $110.5 \pm 36^{c}$ & $189 \pm 49.5^{d}$ & $120 \pm 35^{c}$ & $180 \pm 29.7^{d}$ \\
\hline Conception rate (\%) & $\begin{array}{c}82.4^{\mathrm{a}} \\
(14 / 17)\end{array}$ & $\begin{array}{l}40^{\mathrm{b}} \\
(2 / 5)\end{array}$ & $\begin{array}{l}64.3^{\mathrm{a}} \\
(9 / 14) \\
\end{array}$ & $\begin{array}{l}40^{\mathrm{b}} \\
(2 / 5) \\
\end{array}$ \\
\hline Pregnancy rate $(\%)$ & $\begin{array}{c}53.8^{a} \\
(14 / 26) \\
\end{array}$ & $\begin{array}{l}11.1^{b} \\
(2 / 18) \\
\end{array}$ & $\begin{array}{c}50^{a} \\
(9 / 18) \\
\end{array}$ & $\begin{array}{l}13.3^{b} \\
(2 / 15) \\
\end{array}$ \\
\hline
\end{tabular}

${ }_{\mathrm{a}, \mathrm{b}}$ Values indicated by the same superscript differ significantly within rows: a vs. $b, a>b, P<0.05$ (chisquare test); ${ }^{c, d}$ Values indicated by the same superscript differ significantly within rows: $c$ vs. $d, c<d$, $P<0.05$ (Mann-Whitney U-test).

Oestrus rate $=$ percentage of dairy cattle that underwent oestrus from the total number of dairy cattle included in the group; conception rate = percentage of pregnant dairy cattle out of the overall number of inseminated dairy cattle; pregnancy rate $=$ percentage of pregnant dairy cattle out of the overall number of dairy cattle included in the group.

The treatment protocols for ovarian cysts in dairy cattle are numerous and variable (Peter, 2004). Of the applicable treatment methods, namely manual rupture (Kahn, 2010), cystic fluid aspiration (Amiridis, 2009; Roth et al., 2012) and hormonal application (Gundling et al., 2009; Kawate et al., 2011), the predominant treatment is hormonal application (Taktaz et al., 2015). Bartolome et al. (2005) established that differentiating the type of cyst is not always necessary because treatments for both conditions are similar. However, in situations where it is impossible to distinguish follicular from luteal ovarian cysts, an efficient treatment is supported by GnRH analogues. PGF $2 \alpha$ treatment is favoured when luteal cysts are diagnosed but the same treatment can have reduced efficiency for follicular cysts (Borş et al., 2018). In a previous study we obtained similar results for pregnancy rate $(52.5 \%)$ and calving-to-conception interval (125 days) by treating follicular cysts using a single dose of $21 \mu \mathrm{g}$ buserelin acetate (Borş et al., 2018), compared with this study in which the Ovsynch protocol was used as a supplementary treatment for dairy cattle that did not respond to the first dose of $\mathrm{GnRH}$ analogue. However, the Ovsynch protocol used for treating follicular cysts in dairy cattle generated an improvement in the conception rate, compared with our previous study (conception rate of $67.7 \%$ ) in which a single dose of GnRH was used for treating the same condition. The pregnancy rate in this study is similar to the results obtained by Kawate et al. (2011). Ambrose et al. 


\section{S. I. BORȘ, Alina BORȘ}

(2004) reported a high pregnancy rate (41-46.5\%) following treatment with the Ovsynch protocol that was superior to the results of Abdalla et al. (2020), in which a pregnancy rate of $21.1 \%$ was reported. However, in the study of Abdalla et al. (2020) the first GnRH dose was improperly used in the Ovsynch protocol: by administering a lower GnRH dose than recommended for treating ovarian cysts the protocol efficiency was reduced. In our study, anovular dairy cattle that showed oestrus after the first $\mathrm{GnRH}$ treatment presented new follicles that subsequently ovulated and a higher pregnancy rate, compared with those that received a further Ovsynch protocol, which is in accordance with other studies (Ambrose et al., 2004; Sahu et al., 2015). This means that the first dose of GnRH used, at the high dose recommended for follicular cysts, resulted in the recruitment of a healthy new ovarian follicle in dairy cattle diagnosed with this condition.

To our knowledge, this is the first report of ovarian luteal cyst treatment with PGF $2 \alpha$ or a further 12-day Presynch protocol in dairy cattle that are not responding to the single dose of PGF2 $\alpha$ from Day 0 of the protocol. An improvement in the conception and pregnancy rates was observed by using this strategy, compared with our previous study (conception rate $=56.9 \%$, pregnancy rate $=32.7 \%$ ) in which a single dose of PGF $2 \alpha$ was used (Borş et al., 2018).

This indicates that a single dose of GnRH and, respectively, PGF $2 \alpha$ used for treating ovarian cysts (follicular and luteal, respectively) may not be enough to improve the conception rate in dairy farms. Further treatments with the Ovsynch or 12-day Presynch protocol for ovarian cysts (follicular and luteal, respectively) on multiparous dairy cattle can be considered a good management decision for counteracting the negative effects of this condition.

Furthermore, in both cyst conditions (follicular and luteal), a proportion of multiparous dairy cattle from the MCF and MCL groups showed oestrus without any therapeutic intervention. Dairy cattle that exhibit lower production have an increased chance of spontaneously recovering from cysts that occur in early postpartum. The recovery rate for dairy cattle that presented cysts during first lactation was $80 \%$, whereas for elderly dairy cattle the rate was 30\% (López-Gatius et al., 2002). Despite the reality of ovarian cysts spontaneously recovering, from an economic perspective Brito and Palmer (2004) suggest that treatment should start as soon as this condition is identified. López-Gatius et al. (2002) propose a successful approach that consists of early treatment during postpartum for multiparous dairy cattle that display ovarian cysts and delayed treatment (until the end of the pre-service period at least) for primiparous dairy cattle in order to allow eventual spontaneous recovery to take place. In our study, the low reproductive performance of multiparous dairy cattle that 
spontaneously recovered from ovarian cysts suggests that treatment should be initiated as soon as this condition is diagnosed.

\section{CONCLUSION}

The GnRH analogue or Ovsynch protocol used for treating follicular cysts in multiparous dairy cattle that are not responding to a single dose of GnRH (Day 0) can generate improvement in the conception rate. Also, in luteal cysts the 12-day Presynch protocol can improve the conception rate and the pregnancy rate in multiparous dairy cattle that are not responding to a single dose of PGF2 $\alpha$. Although spontaneous recovery from cysts does occur, an efficient reproductive response can be obtained by initiating treatment as soon as this condition is diagnosed. Furthermore, this strategy can reduce the excessive use of hormones in the dairy industry, with supplementary hormonal doses only being administered by the Ovsynch and 12-day Presynch protocols for those dairy cattle diagnosed with ovarian cysts that do not recover after a single hormonal dose.

Acknowledgements. The authors of this paper wish to express their gratitude to Simona Vlad-Sabie for her valuable criticism of the manuscript and for the English review. The research was supported by a grant from the Romanian Ministry of Agriculture and Rural Development (ADER 8.3.4/2019).

\section{REFERENCES}

Abdalla, H., de Mestre, A.M. \& Salem, S.E. (2020). Efficacy of ovulation synchronization with timed artificial insemination in treatment of follicular cysts in dairy dairy cattle. Theriogenology, 154: 171-180, DOI: 10.1016/j.theriogenology.2020.05.02 9

Amiridis, G.S. (2009). Comparison of aspiration and hormonal therapy for the treatment of ovarian cysts in dairy cattle. Acta. Vet.Hung., 57: 521529, DOI: 10.1556/AVet.57.2009.4.6

Ambrose, D.J., Schmitt, E.J.P., Lopes, F.L., Mattos, R.C. \& Thatcher, W.W. (2004). Ovarian and endocrine responses associated with the treatment of cystic ovarian follicles in dairy dairy cattle with gonadotropin releasing hormone and prostaglandin F2 alpha, with or without exogenous progesterone. Can.Vet.J., 45(11): 931-937.

Bartolome, J.A., Thatcher, W.W., Melendez, P., Risco, C.A. \& Archbald, L.F. (2005). Strategies for the diagnosis and treatment of ovarian cysts in dairy cattle. J.Am.Vet.Med.Assoc., 227: 14091414, DOI: 10.2460/javma.2005. 227.1409

Borș, S.I. \& Borș, Alina (2020). Ovarian cysts, an anovulatory condition in dairy cattle. Advance online Publication. J.Vet.Med.Sci., 82(10): 1515-1522, DOI: 10.1292/jvms.200381

Borș, S.I., Ibănescu, I., Creangă, Ș. \& Borș, Alina (2018). Reproductive performance in dairy dairy cattle with cystic ovarian disease after single treatment with buserelin acetate or dinoprost. J.Vet.Med.Sci., 80(7): 1190-1194, DOI: 10.1292/jvms.170690.

Brito, L.F.C. \& Palmer, C.W. (2004). Cystic ovarian disease in cattle. Large Anim. Vet. Rounds, 4: 1-6.

Gundling, N., Drews, S. \& Hoedemaker, M. (2009). Comparison of two different programmes of ovulation 


\section{S. I. BORȘ, Alina BORȘ}

synchronization in the treatment of ovarian cysts in dairy dairy cattle. Reprod.Domest.Anim., 50(6): 893900, DOI: 10.1111/j.1439-0531.20 09.01342.x

Jeengar, K., Chaudhary, V., Kumar, A., Raiya, S., Gaur, M. \& Purohit, G.N. (2014). Ovarian cysts in dairy dairy cattle: old and new concepts for definition, diagnosis and therapy. Anim.Reprod., 11(2): 63-73.

Kahn, C.M. (2010). Cystic ovary disease (pp. 1243-1247). In: The Merck veterinary manual, 10th ed. (Kahn, C.M. and Line, S., Eds.), Whitehouse Station, N.J.: Merck \& Co., Inc., 2010.

Kawate, N., Watanabe, K., Uenaka, K., Takahashi, M., Inaba, T. \& Tamada, H. (2011). Comparison of plasma concentrations of estradiol$17 \beta$ and progesterone, and conception in dairy dairy cattle with cystic ovarian diseases between Ovsynch and Ovsynch plus CIDR timed Al protocols. J.Reprod. Develop., 57(2): 267-272, DOI: 10.1262/jrd.10-066t

López-Gatius, F., Santolaria, P., Yániz, J., Fenech, M. \& López-Béjar, M. (2002). Risk factors for postpartum ovarian cysts and their spontaneous recovery or persistence in lactating dairy dairy cattle. Theriogenology, 58(8): 1623-1632, DOI: 10.1016/s00 93-691x(02)01046-4

Opsomer, G., Coryn, M., Deluyker, H. \& de Kruif, A. (1998). An analysis of ovarian dysfunction in high yielding dairy dairy cattle after calving based on progesterone profiles. Reprod.Domest.Anim., 33: 193-204,
DOI: 10.1111/j.1439-0531.1998.tb01 342.x

Peter, A.T. (2004). An update on cystic ovarian degeneration in cattle. Reprod.Domest.Anim., 39(1): 1-7, DOI: $\quad 10.1046 / \mathrm{j} .0936-6768.2003 .00$ 466.x

Roth, Z., Biran, D., Lavon, Y., Dafni, I., Yakobi, S. \& Braw-Tal, R. (2012). Endocrine milieu and development dynamics of ovarian cysts and persistent follicles in postpartum dairy dairy cattle. J. Dairy Sci., 95(4): 1729-1737, DOI: 10.3168/jds.20114513

Sahu, S.K., Cockrem, J.F., Parkinson, T.J. \& Laven, R.A. (2015). Effects of progesterone inclusion in a gonadotropin-prostaglandin-gonado tropin programme on follicular dynamics and ovulation synchronisation of pasture-based dairy dairy cattle with anoestrous. Res.Vet Sci.,102: 200-205, DOI: 10.1016/j.rvsc.2015.08.015

Taktaz, T., Kafi, M., Mokhtari, A. \& Heidari, M. (2015). Reproductive responses of dairy dairy cattle with ovarian cysts to simultaneous human chorionic gonadotropin or gonadotropin-releasing hormone and cloprostenol compared to gonadotropin-releasing hormone alone treatment. Vet. World, 8(5): 640-644, DOI: 10.14202/vetworld.20 15.640-644

Vanholder, T., Opsomer, G. \& de Kruif, A. (2006). Aetiology and pathogenesis of cystic ovarian follicles in dairy cattle: a review. Reprod.Nutr.Dev., 46(2): 105-119, DOI: 10.1051/rnd:20 06003 . 